\title{
Nuclear fusion and its large potential for the future world energy supply
}

\begin{abstract}
An overview of the energy problem in the world is presented. The colossal task of 'decarbonizing' the current energy system, with $\sim 85 \%$ of the primary energy produced from fossil sources is discussed. There are at the moment only two options that can contribute to a solution: renewable energy (sun, wind, hydro, etc.) or nuclear fission. Their contributions, $\sim 2 \%$ for sun and wind, $\sim 6 \%$ for hydro and $\sim 5 \%$ for fission, will need to be enormously increased in a relatively short time, to meet the targets set by policy makers. The possible role and large potential for fusion to contribute to a solution in the future as a safe, nearly inexhaustible and environmentally compatible energy source is discussed. The principles of magnetic and inertial confinement are outlined, and the two main options for magnetic confinement, tokamak and stellarator, are explained. The status of magnetic fusion is summarized and the next steps in fusion research, ITER and DEMO, briefly presented.
\end{abstract}

Key words: energy $\bullet$ nuclear fusion $\bullet$ tokamak $\bullet$ stellarator

\author{
J. Ongena \\ Plasma Physics Laboratory, \\ Royal Military Academy, \\ Partner in the Trilateral Euregio Cluster (TEC), \\ Renaissancelaan 30, 1000 Brussels, Belgium, \\ Tel.: +32 24414 119, Fax: +32 273524 21, \\ E-mail: j.ongena@fz-juelich.de
}

Received: 12 July 2015

Accepted: 19 April 2016

\section{Introduction}

Climate and energy are getting an ever increasing attention in recent years. Worrying phenomena such as extreme droughts and rainfall, tremendous tropical storms and melting of glaciers and ice at the poles are becoming regular news items. Many animal species are becoming extinct at a very fast rate, such that some media start to speak of a new 'mass extinction'. The human being could well be one of the species suffering from the destruction of our habitat in the near or far future.

Alarming Intergovernmental Panel on Climate Change (IPCC) reports claim an increase in the temperature of a few degrees in the coming decades because of the continuous release of $\mathrm{CO}_{2}$ and other greenhouse gases in the atmosphere. The Heads of State at the G7 conference in May 2015 prepared for the first time bold statements, declaring their intention to decarbonize the world energy production. However, such decisions, if not prepared correctly, could have unwanted negative effects. Technology development times and realistic potentials of the various options need to be taken into account.

This paper is intended to document the energy problem and to discuss possible solutions for the future and to highlight the role of fusion energy to contribute to a 'decarbonized' energy system. 
To start the discussion, let us look at the energy consumption in the world now and in the future. With about 7.2 billion people on Earth in 2015 and a primary power consumption per capita (world average) of about $2.5 \mathrm{~kW}$, the total amount of energy currently consumed is about $2.5 \mathrm{~kW} \times 7.2$ billion people $\times 1$ year is $17.5 \mathrm{TWyr}$.

An estimate of what might be needed in the future can be found with the following two assumptions: (i) primary power consumption per capita (world average) remains the same or increases further to about $3 \mathrm{~kW}$ (note that this is about half of what is already used in Europe and one-fourth of what is currently used in the United States), and (ii) world population will stabilize at a number between 8 and 12.5 billion people (minimum and maximum predictions by the United Nation [1]).

Thus, in 50 years, we expect the world to consume yearly an amount of primary energy equal to $(2.5-3) \mathrm{kW} \times(8-12.5)$ billion people $\times 1$ year $=$ 20-37.5 TWyr. This is between 1.2 and 2.2 times the current energy consumption.

If we believe these numbers, this would be equivalent to an increase of minimum $2.5 \mathrm{TWyr}$ and maximum 20 TWyr in 50 years time or an increase of minimum $50 \mathrm{GW}$ and maximum about $400 \mathrm{GW}$ installed power per year. In practice, this would mean having to build at least one large power plant every week or in the worst case more than one every day, somewhere in the world!

Is this possible? In fact, it is already happening in just one country in the world. China alone constructed about $60 \mathrm{GW}$ of additional electric power generation from fossil sources past year. This is more than one new plant per week, mostly burning coal, in just one country in the world.

But existing systems will also need to be replaced, first of all because of aging, but most importantly to convert them into much more environmentally friendly systems. Thus we have to nearly double the effort.

To further realize the task that lays in the front of us, Table 1 shows the current contribution of various energy sources to the primary energy production in the world [2]. We immediately note the overwhelming dominance of fossil sources, which contribute $\sim 85 \%$ of the world primary energy production. The rest, $\sim 15 \%$, is thus the contribution from non-fossil options: hydro, wind and solar and nuclear fission. If nuclear fission is dismissed then the candidate replacement options contribute now for a mere $\sim 10 \%$. This clearly shows the staggering task that

Table 1. Contribution of various energy sources to the primary energy production in the world

\begin{tabular}{lc}
\hline $\begin{array}{c}\text { Primary energy } \\
\text { source }\end{array}$ & $\begin{array}{c}\text { Contribution to primary } \\
\text { energy production (2012) } \\
\end{array}$ \\
\hline Oil & $3 \%]$ \\
Coal & 35.4 \\
Gas & 28.7 \\
Fission & 22.7 \\
Hydro-electricity & 6.8 \\
Solar, wind, wood, waste, etc. & 4.4 \\
\hline
\end{tabular}

lies before us: we need to crank up the contribution of the non-fossil options at least five times if we want to arrive at a fully decarbonized energy production. Renewable energy will have to play an important role in the future. But we need to realize that although renewable energy resources in the world are large and inexhaustible, they have, unfortunately, serious drawbacks [3]. One of them is their low energy density, another one is the inherent huge fluctuations in time, which in addition are often difficult to predict. This is not easy to cope with, surely if the amplitude of the fluctuations is large. It could even be a major impediment to exploit their full potential. In the case of electricity production, a solution to this problem could consist in colossal electricity storage systems, non-existent at the scale needed (hundreds of gigawatt hours of energy in a few hours in the case of, for example, wind in Germany). A massive research and development programme is urgently needed to develop such large systems at an affordable cost, in so far as technically possible.

Moreover, backup power capacity will be needed for those days where sun, wind or the storage cannot supply the power needed. This backup capacity has - by definition - to be different from renewable and thus can only be fossil or nuclear fission. But if the energy system has to be decarbonized and nuclear fission is not accepted, then we have a problem. Thus any additional energy source, free from the production of $\mathrm{CO}_{2}$, such as fusion, is very much needed.

To be correct, we should also take into account indirect emissions. These indirect emissions arise from construction, mining and transportation of the fuel and so on, that is, all the phases in the life and operation of a power plant different from power generation. In the case of nuclear fission, this arises mainly from the construction and maintenance of the plant and from mining and processing ore. But this is only a minor effect. For fusion, this would also be from construction and maintenance of the plant and from processing the fuel. But as the fuel consumption is low and consists of abundant Li and $\mathrm{D}$, this is again a minor effect. In the case of renewables, the low power density, illustrated in Table 2, unavoidably implies considerable land use and/or investment in materials. For example, in the case of biomass, this implies areas of several thousand square kilometer even for a relatively low power production of $100 \mathrm{MW}$, and $\mathrm{CO}_{2}$ emissions from fertilizer/pesticide production, harvesting, drying, and transportation have to be taken into account. It leads for some 'low carbon' technologies to a serious decrease in their potential to contribute effectively to $\mathrm{CO}_{2}$ reductions, or depending on the case, even to a further increase in $\mathrm{CO}_{2}$ emissions! For an interesting analysis, see $[4,5]$. The production of, for example, solar cells causes quite some pollution if one is not careful and have already led to local protests and resulting closure of solar panel factories, for example, in China [6]. Some of the estimates of the worldwide potential also seem not to take into account fundamental restrictions. For example, in the case of wind energy, a bottom-up estimation seems to easily lead to overestimations [7]. 
Table 2. Power production per square metre of land or sea surface occupied. Renewable energy is rather diffuse, leading to large, country-sized facilities in order to contribute substantially (from [3])

\begin{tabular}{|c|c|c|}
\hline $\begin{array}{c}\text { Renewable } \\
\text { category }\end{array}$ & $\begin{array}{l}\text { Renewable } \\
\text { source }\end{array}$ & $\begin{array}{c}\text { Power } \\
\text { output } \\
{\left[\mathrm{W} / \mathrm{m}^{2}\right]}\end{array}$ \\
\hline \multirow{7}{*}{$\begin{array}{l}\text { Sun } \\
\text { based }\end{array}$} & Solar heating & 53 \\
\hline & Concentrating solar power (deserts) & 15 \\
\hline & Solar photovoltaics & $5-20$ \\
\hline & Solar chimney & 0.1 \\
\hline & Ocean thermal & 5 \\
\hline & Wind & $2-3$ \\
\hline & Waves (Pelamis farms) & 30 \\
\hline \multirow{3}{*}{$\begin{array}{l}\text { Gravitation } \\
\text { based }\end{array}$} & Tidal power & 6 \\
\hline & Tide pool & 3 \\
\hline & Hydro-electricity & 11 \\
\hline \multirow{5}{*}{$\begin{array}{l}\text { Agriculture } \\
\text { based }\end{array}$} & Biogas & 0.02 \\
\hline & Rape seed oil & 0.13 \\
\hline & Bio-ethanol (sugar cane) & 1.2 \\
\hline & Energy crops & 0.5 \\
\hline & Wood & $0.1-0.2$ \\
\hline Earth based & Geothermal heat & 0.017 \\
\hline
\end{tabular}

For a very interesting discussion on sustainability, energy efficiency and subsidies, see [8]; a critical assessment of the consequences of the recent German energy policy, so often praised for its green energy policy, is given in $[9,10]$. These and other arguments should be carefully taken into account in discussing future energy options.

\section{Nuclear fusion}

From the above, it is clear that any additional energy source in the future will be very welcome. Fusion is still in development as we all know, but it holds the promise of being a safe, practically inexhaustible and rather clean energy production method. As such it could become the best compromise between nature and the energy needs of mankind. The reaction in the Sun transforms $\mathrm{H}$ nuclei to ${ }^{4} \mathrm{He}$ nuclei using the so-called p-p reaction chain, a complex set of reactions that starts from four protons and ends up in a ${ }^{4} \mathrm{He}$ nucleus. The ${ }^{4} \mathrm{He}$ nucleus contains, however, two neutrons, so there is a conversion needed from proton to neutron. This is the slowest part in the $\mathrm{p}-\mathrm{p}$ chain and is possible via inverse $\beta$ decay, a very slow reaction. For this reason, the process on the Sun cannot be used on Earth; it will never lead to an economical reactor. A clever trick is to use isotopes of $\mathrm{H}$ as fuel, which already contains the necessary neutrons for the synthesis of ${ }^{4} \mathrm{He}$. Thus the nuclides need only to be 'rearranged', a process that is much faster. Measured data for a number of fusion reactions $[11,12]$ between light nuclei containing neutrons are listed in Table 3 . The fusion reaction that shows the best combination of a large cross section and large energy gain is the so-called D-T reaction:

$$
\text { (1) } \mathrm{D}+\mathrm{T} \rightarrow{ }^{4} \mathrm{He}(3.5 \mathrm{MeV})+\mathrm{n}(14.1 \mathrm{MeV})
$$

where D symbolizes deuterium (the stable isotope of hydrogen with a nucleus consisting of one proton and one neutron) and $\mathrm{T}$ is the symbol for tritium (the radioactive hydrogen isotope with a nucleus of two neutrons and one proton).

The reaction products are an $\alpha$-particle $\left({ }^{4} \mathrm{He}\right.$ nucleus) and a neutron. Consistent with recoil momentum balance in the nuclear disintegration process, the energy of the five times lighter neutron is five times higher than that of the heavier $\alpha$-particle, as indicated in Eq. (1). In magnetic confinement systems, the neutron does not feel the presence of the magnetic field (because of its neutrality) and escapes immediately from the reactor volume, while the charged $\alpha$-particle is confined. The kinetic energy of these escaping fast neutrons will be converted into heat in a blanket and then into electricity using conventional technology (steam). About one million times more energy is released from a fusion reaction in comparison with a chemical one (megaelectron-volts instead of electron-volts for the latter). This is the reason why so little fuel can produce so much energy: when burnt in a fusion reactor, the deuterium contained in 11 of ordinary water (about $33 \mathrm{mg}$ ) will produce as much energy as burning 2601 of gasoline.

Other possible fusion reactions of interest between isotopes of hydrogen and helium are

Table 3. Measured data for a number of fusion reactions between light nuclei containing neutrons, together with their cross sections $\sigma$ at the centre-of-mass energy of $10 \mathrm{keV}$, the maximum cross section $\sigma_{\max }$ (in barn), the location of the maximum $\varepsilon_{\max }$ and the energy released per reaction (in $\mathrm{MeV}$ ). In the line for the p-p reaction, $1.44 \mathrm{MeV}$ is the energy in the positron and deuteron and $0.27 \mathrm{MeV}$ is the average energy in the neutrino [11]

\begin{tabular}{lcccc}
\hline \multicolumn{1}{c}{ Reaction } & $\begin{array}{c}\sigma \text { at } 10 \mathrm{keV} \\
{[\text { barn }]}\end{array}$ & $\begin{array}{c}\sigma_{\max } \\
{[\text { barn }]}\end{array}$ & $\begin{array}{c}\text { Centre of mass energy } \\
{[\mathrm{keV}] \text { for } \sigma_{\max }}\end{array}$ & $\begin{array}{c}\text { Energy released } \\
{[\mathrm{MeV}]}\end{array}$ \\
\hline $\mathrm{D}+\mathrm{T} \rightarrow{ }^{4} \mathrm{He}+\mathrm{n}$ & $2.72 \times 10^{-2}$ & 5.0 & 64 & 17.59 \\
$\mathrm{D}+\mathrm{D} \rightarrow \mathrm{T}+\mathrm{p}$ & $2.81 \times 10^{-4}$ & 0.096 & 1250 & 4.04 \\
$\mathrm{D}+\mathrm{T} \rightarrow{ }^{3} \mathrm{He}+\mathrm{n}$ & $2.78 \times 10^{-4}$ & 0.11 & 1750 & 3.27 \\
$\mathrm{~T}+\mathrm{T} \rightarrow{ }^{4} \mathrm{He}+2 \mathrm{n}$ & $7.90 \times 10^{-4}$ & 0.16 & 1000 & 11.33 \\
$\mathrm{D}+{ }^{3} \mathrm{He} \rightarrow{ }^{4} \mathrm{He}+\mathrm{p}$ & $2.20 \times 10^{-7}$ & 0.9 & 250 & 18.35 \\
$\mathrm{p}+{ }^{6} \mathrm{Li} \rightarrow{ }^{4} \mathrm{He}+{ }^{3} \mathrm{He}$ & $6.00 \times 10^{-10}$ & 0.22 & 1500 & 8.02 \\
$\mathrm{p}+{ }^{11} \mathrm{~B} \rightarrow 3{ }^{4} \mathrm{He}$ & $4.60 \times 10^{-17}$ & 1.2 & 550 & $1.44+0.27(v)$ \\
$\mathrm{p}+\mathrm{p} \rightarrow \mathrm{D}+\mathrm{e}^{+}+v$ & $3.60 \times 10^{-26}$ & - & - & 1.94 \\
$\mathrm{p}+{ }^{12} \mathrm{C} \rightarrow{ }^{13} \mathrm{~N}+\gamma$ & $1.90 \times 10^{-26}$ & $1.0 \times 10^{-4}$ & 400 & \\
\hline
\end{tabular}


(2) $\mathrm{D}+\mathrm{D} \rightarrow{ }^{3} \mathrm{He}(0.82 \mathrm{MeV})+\mathrm{n}(2.45 \mathrm{MeV})$

$$
\mathrm{D}+\mathrm{D} \rightarrow \mathrm{T}(1.01 \mathrm{MeV})+\mathrm{H}(3.02 \mathrm{MeV})
$$

(4) $\mathrm{D}+{ }^{3} \mathrm{He} \rightarrow{ }^{4} \mathrm{He}(3.6 \mathrm{MeV})+\mathrm{H}(14.7 \mathrm{MeV})$

They require higher temperatures and are thus more difficult to achieve and have a lower power density than the D-T reaction $[11,12]$ but show even more benign environmental features. The $\mathrm{D}$-D reaction would eliminate the need for tritium and produce neutrons with lower energies that are, therefore, easier to absorb and shield. A reactor based on the D- ${ }^{3} \mathrm{He}$ reaction would proceed with very low neutron production (some neutrons would be produced in competing but much less occurring D-D reactions) and lead to much less induced radioactivity in the reactor structures. However, the prospects for these 'advanced' fuels are still too speculative and only the D-T reaction has immediate future prospects.

\section{Advantages of fusion power}

A close look at the D-T fusion reaction, the reaction to be used in first fusion reactors, shows immediately the nice prospects of fusion.

1. The reactants are D and T. D can be obtained from seawater with conventional techniques in a cheap way $(1 / 6000$ of all hydrogen on Earth consists of D); $\mathrm{T}$ is the radioactive isotope of hydrogen. It decays to ${ }^{3} \mathrm{He}$ by the emission of an electron, with the rather short half-life of 12.3 years:

$$
\mathrm{T} \rightarrow{ }^{3} \mathrm{He}+\mathrm{e}^{-}+18.7 \mathrm{keV}
$$

Aside from on estimated $10 \mathrm{~kg}$ of $\mathrm{T}$ produced by cosmic rays in the upper atmosphere, it is thus essentially non-existent in nature and will have to be artificially made. The neutrons produced in the fusion reactions will be used to breed it by bombarding a blanket around the burn chamber containing a lithium compound, according to

$$
\begin{gathered}
{ }^{6} \mathrm{Li}+\mathrm{n} \rightarrow{ }^{4} \mathrm{He}(2.05 \mathrm{MeV})+\mathrm{T}(2.73 \mathrm{MeV}) \\
{ }^{7} \mathrm{Li}+\mathrm{n} \rightarrow{ }^{4} \mathrm{He}+\mathrm{T}+\mathrm{n}-2.47 \mathrm{MeV}
\end{gathered}
$$

Thus the main inputs to a fusion reactor are D and $\mathrm{Li}$, two products that are abundant and free from any radioactivity.

2. Nearly inexhaustible source of energy. Very little fuel consumption for a huge amount of energy. To supply an 'average' EU citizen with electricity during 80 years (assuming the use of steam turbines, and taking into account the efficiency of the conventional Carnot cycle of 35-40\%) only about $15 \mathrm{~g}$ of a mixture of $\mathrm{D}$ and $\mathrm{T}$ is needed. Taking into account the reserves of $\mathrm{D}$ in seawater and the terrestrial reserves of $\mathrm{Li}$, one finds easily that fusion is a source for several thousand years, if based on the D-T reaction. If later the $\mathrm{D}-\mathrm{D}$ reaction could be used, then we would have a source of energy for millions of years.
3. Strongly reduced energy dependency. The fact that $\mathrm{D}$ and $\mathrm{Li}$ are abundant and cheap reduces to a large extent the dependence on foreign countries to deliver fuel. This is an important element in the discussion on world peace. It also avoids the enormous concentration of money in the oil-rich regions of the world, with all the very negative consequences we see happening in the past decades.

4. No long-term storage of nuclear waste. There is radioactivity from two sources: (i) tritium is radioactive but is fuel for the reaction. (ii) The 14.1 MeV neutron will induce activity in the structural elements of the reactor. But this can be minimized by making a good choice for the structural elements in the reactor, in the sense that one would look for materials with a short half-life ( $\sim 50-100$ years) after irradiation with the 14.1 MeV neutrons. Owing to the specific spectrum of the neutrons, a dedicated test facility will have to be built that can test the proposed material solutions. Such a facility is IFMIF (International Fusion Materials Irradiation Facility). Poland recently declared its expression of interest in being the host for such a facility. Prototype elements for IFMIF are in construction and under test in Japan, Italy and Germany [13, 14].

5. Safety. Fusion reactions take place at extremely high temperatures $(\sim 150$ million degrees, see below) and the fusion process in itself does not consist in a neutron multiplication reaction. (Note that a careful addition of a neutron multiplier (e.g. $\mathrm{Be}, \mathrm{Pb}$ ) will be needed to compensate unavoidable losses, but this will not lead to a severe multiplication of neutrons as in the case of the fission reaction where by every reaction, approximately three new neutrons are born). An uncontrolled burn (nuclear runaway) of the fusion fuel is, therefore, excluded on physical grounds. In addition, the amount of fuel (D and T) available at each instant is sufficient for operation during only a few seconds, in sharp contrast with a fission reactor where fuel for several years of operation is stored in the reactor core. Third, residual heating is not sufficient to cause melting of the reactor structure. Even in case of a total loss of active cooling, no safety problems are expected [15].

\section{Confinement of the hot plasma}

Two approaches are currently being investigated to confine the hot plasma: inertial and magnetic confinement. In the first approach, lasers or particle beams are used to rapidly compress the nuclear fuel in order to achieve the conditions required for fusion. To this end, a small sphere with a diameter of $\sim 1 \mathrm{~mm}$ is filled with equal amounts of deuterium and tritium.

Powerful laser or particle beams irradiate the surface of this little sphere as uniformly as possible for a very short time $\left(\sim 10^{-9} \mathrm{~s}\right)$. This sphere is covered with a layer that easily absorbs the power of the beams, and this shell vapourizes nearly immediately, generating an inward-propagating spherical shock wave, which causes an enormous compression of the sphere's 
contents. At the end of this short compression phase, a density of a thousand times that of water is reached at a temperature of some tens of millions of degree centigrade. Under these conditions, the deuterium and tritium nuclei start to fuse. The energy released by these first fusion reactions further heats the rest of the strongly compressed fuel, allowing fusion reactions to spread throughout the whole sphere.

The second approach is by magnetic confinement. This approach uses the fact that at the high temperatures necessary for nuclear fusion, the fuel becomes nearly fully ionized. This then offers the nice possibility to make use of magnetic fields to confine the fuel, because charged particles will follow a helical path around the field lines owing to the Lorentz force. With an appropriate geometry for the magnetic field, it is thus possible to keep the hot particles away from the walls of the container.

In a tokamak, a set of coils placed around the doughnut-shaped plasma chamber produces the main toroidal magnetic field. The conducting plasma ring itself serves as the sole secondary winding of an enormous transformer. A current pulse in the primary winding induces a large current in the secondary, that is, in the plasma ring itself. This induced plasma current is accompanied by a poloidal magnetic field. The combination of this poloidal field with the main toroidal field results in a helical magnetic field (Fig. 1). The magnetic structure thus generated consists of an infinite set of nested toroidal magnetic

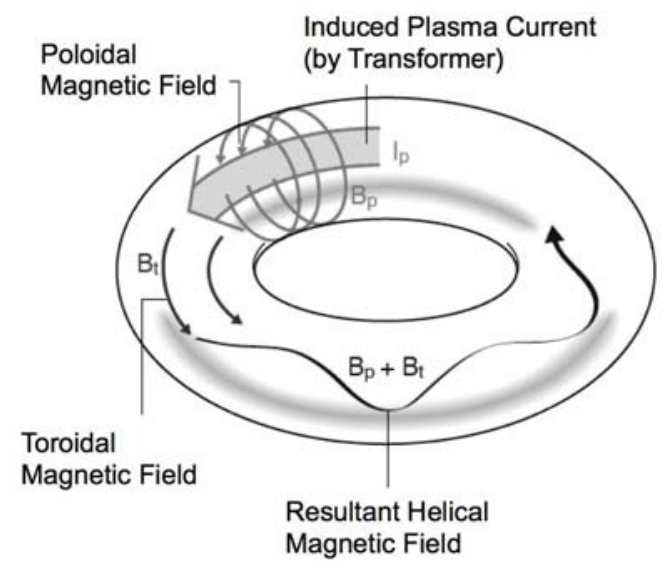

Fig. 1. In a tokamak, the combination of the poloidal field generated by the plasma current and the main toroidal field generated by external toroidal field coils results in the helical magnetic field, necessary for the stability of the plasma.

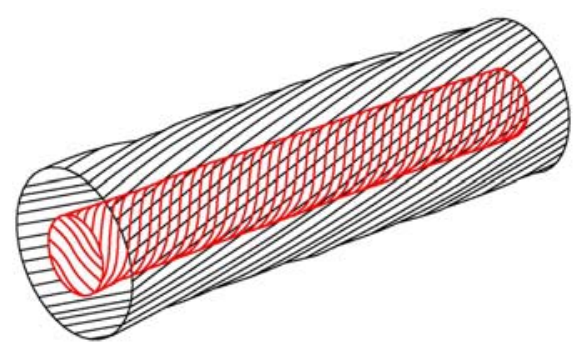

Fig. 2. A simplified, but for didactical purposes greatly exaggerated, example showing the magnetic structure in a tokamak: a set of nested toroidal magnetic surfaces, each with a different twist. The innermost surfaces have the largest twist. surfaces (Fig. 2), each with a slightly different twist, reducing further the leakage of particles and heat from the plasma. On each of these surfaces, the plasma pressure is constant.

The tokamak is an intrinsically pulsed device, because the transformer that induces the plasma current needs a steadily increasing current to provide the necessary change in magnetic flux that induces the current in the plasma ring. One could argue that non-inductive current drive (e.g. by electromagnetic waves and injection of fast particles unidirectionally on axis) could solve this problem. The reality is, however, that the current drive efficiency of all known systems is rather low. They thus consume large amounts of energy to produce a given plasma current. For a future fusion reactor, present knowledge indicates that the so-called re-circulating power will be increased to such an extent that it becomes questionable if non-inductive current drive will ever be useful.

Continuous operation of a fusion device can be obtained if the need for inducing a plasma current could be avoided. The stellarator is such a solution, and it relies on currents external to the plasma for the helical magnetic configuration. In its basic configuration, extra helical coils around the toroidal plasma provide the necessary additional twist to the toroidal magnetic field generated by the main field coils (Fig. 3). Initial stellarator configurations lacked good confinement properties. Modern stellarators have optimized confinement properties and are equipped with a complex set of coils that are determined numerically (Fig. 4). Several devices

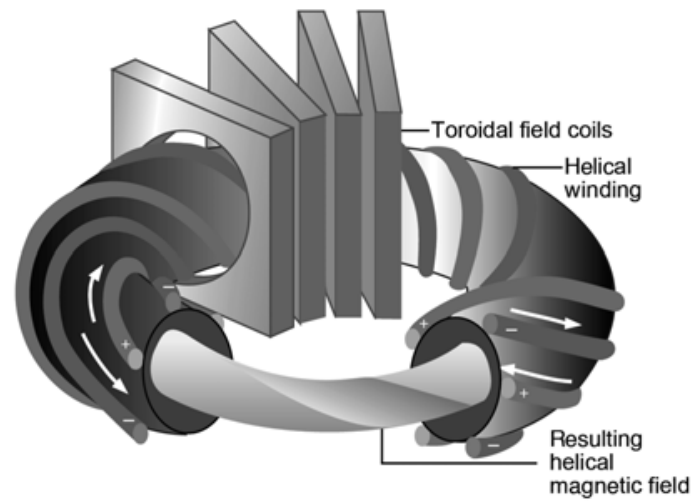

Fig. 3. Magnet system from the early stellarators: extra helical coils provide the necessary additional twist to the toroidal magnetic field generated by the main field coils.

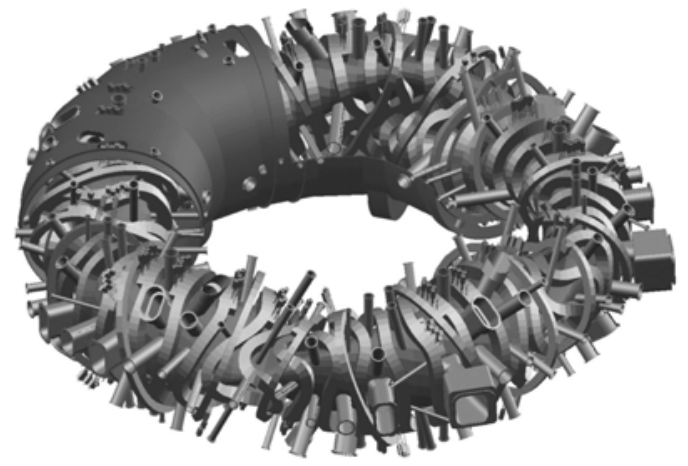

Fig. 4. Modern stellarators have optimized confinement properties and are equipped with a complex set of coils that are determined numerically. 


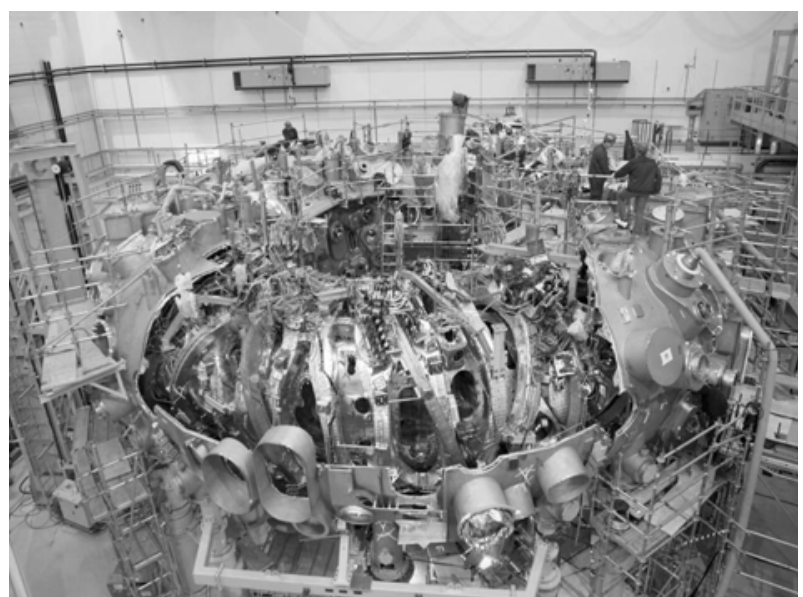

Fig. 5. A picture of Wendelstein 7-X in Greifswald, during its construction phase a few years ago.

of the stellarator type are in operation or construction at this moment all over the world. The largest stellarator currently that is now in its startup phase is Wendelstein 7-X, Greifswald, Germany (Fig. 5).

The temperatures required for fusion can be reached with two main types of heating systems. The first type consists of accelerating $\mathrm{H}$, D or $\mathrm{He}$ ions to high energies (in current tokamaks up to $\sim 150 \mathrm{keV}$, in future fusion reactors up to approximately megaelectron-volts per particle) and injecting them into the plasma. A complication is caused by the confining magnetic field. If the fast particles are charged, they will be deflected by the magnetic field and not be able to enter the hot plasma.

Therefore, the accelerated ions must be neutralized before they can penetrate into the hot plasma. To this end, the highly energetic ions are sent through a cloud of neutral gas. The accelerated ions 'steal' electrons from atoms in this neutral gas cloud and become energetic neutral particles and will pass the magnetic field unhindered. Once in the hot plasma, they are almost immediately ionized again and deposit their energy via collisions to the rest of the plasma particles. Powers of up to several million watts per neutral injector can be delivered in this way.

A second heating method is based on electromagnetic waves. The waves are coupled to the plasma by antennas or waveguides at the plasma edge. The energy from the waves is most easily absorbed if the frequency used is equal to a 'natural' frequency of the particles to be heated. The cyclotron frequency, with which the charged plasma particles gyrate around the magnetic field lines, is such a frequency, and one has the choice between ions and electrons, resulting in ion cyclotron resonance heating and electron cyclotron resonance heating systems. Ion cyclotron frequencies are in the megahertz range (20 $\mathrm{MHz}$ and upwards), while electron cyclotron frequencies are approximately a 1000 times higher (up to $200 \mathrm{GHz}$ ), because of the smaller mass of the electrons. Heating powers for high-frequency systems range from $100 \mathrm{~kW}$ to several tens of megawatts. A third system exists (lower hybrid heating) that uses frequencies in between those from electrons and ions and is mostly used to drive part of the plasma current.

\section{Characterizing the performance of fusion plasmas}

The power amplification factor Q is defined as the ratio of the power produced by fusion reactions to the total heating power supplied externally. Two important milestones for the value of $\mathrm{Q}$ are customarily used in fusion research. The first, breakeven, is reached when the heating power is equal to the power produced from fusion reactions, corresponding to a $\mathrm{Q}$ value of one. The second, ignition, is reached when the additional heating systems can be switched off and the heat of the fusion reactions alone is sufficient to maintain the high temperatures needed for fusion. This corresponds to an infinite value for $\mathrm{Q}$.

The most impressive results in fusion research up to now were obtained in the Joint European Torus (JET), in October and November 1997. Experiments in $50 \% \mathrm{D}-50 \% \mathrm{~T}$ plasmas resulted in more than $16 \mathrm{MW}$ of fusion power during about $1 \mathrm{~s}$, with Q values in excess of 0.7 [16]. These are the highest fusion powers and $\mathrm{Q}$ values ever reached, thereby effectively resulting in the first demonstration of breakeven in reactor grade D-T fusion plasmas. A quasi steady-state generation of fusion power has also been demonstrated: more than $4 \mathrm{MW}$ of fusion power were produced for time intervals of more than $5 \mathrm{~s}$ [17], a duration only limited by the actual technical constraints of JET.

A summary of the different high-performance D-T pulses obtained on JET and Tokamak Fusion Test Reactor (TFTR), as discussed earlier, is presented in Fig. 6.

The results obtained at JET and other smaller machines provide crucial information for the design of a next large tokamak, aimed at demonstrating the technical feasibility for large-scale energy production. This next step is ITER, originally short for International Thermonuclear Experimental Reactor, currently under construction in Cadarache, France as a combined effort between Europe, Japan, the Russian Federation, South Korea, India, China and

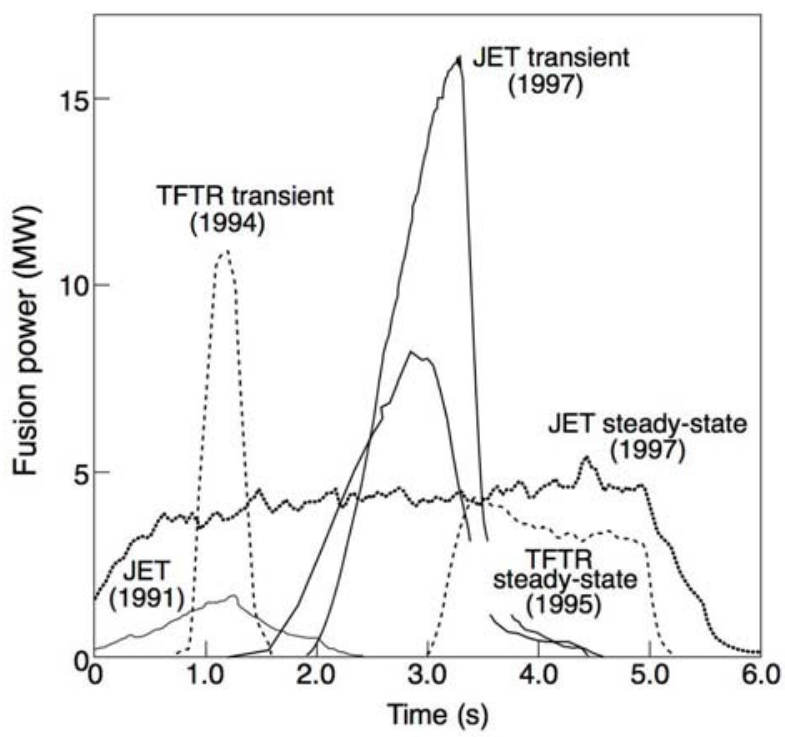

Fig. 6. A summary of different high-performance D-T pulses obtained on JET and TFTR. 


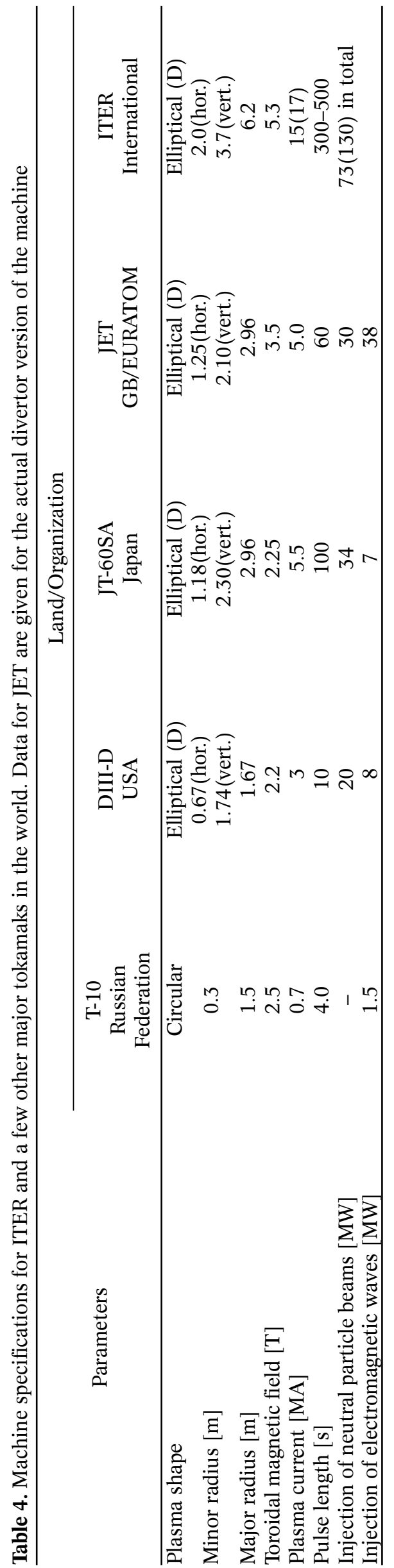

the United States. This device will thus for the first time in history allow mankind to produce huge quantities of energy from nuclear fusion reactions in a controlled way at temperatures of more than 100 million degrees. ITER is expected to generate fusion powers of the order of $500 \mathrm{MW}$ in pulses of 300-500 s. Specifications for ITER (and a few other major tokamaks) are summarized in Table 4. After ITER, the construction of a demonstration reactor is foreseen, currently termed DEMO, which should show not only the technical but also the economical feasibility of fusion.

\section{Conclusions}

Some decades will still be needed to realize a practically useable energy source based on the D-T fusion reaction. The most recent results support the attractiveness of the fusion concept for energy production and have led to the definition of ITER, the next large tokamak, now in construction in Cadarache, France. There is no doubt that fusion is a challenging undertaking and that patience is needed, but it is more than worth the effort given the (rather enormous) difficulties we are facing for the future world energy supply. It will be evidently up to the new generation of young researchers, to tackle these interesting and very important problems. If successful, this will be your vitally important contribution to the benefit of all people on Earth.

An enormous challenge, but with an immense reward!

\section{References}

1. United Nations. (2013). World population prospects: the 2012 revision. New York: UN. Retrieved from https://esa.un.org/unpd/wpp/publications/Files/ WPP2012 HIGHLIGHTS.pdf.

2. U.S. Energy Information Administration. (2015). International energy statistics. Retrieved from http:// www.eia.gov/cfapps/ipdbproject/IEDIndex3.cfm.

3. MacKay, D. J. C. (2009). Sustainable energy - without the hot air. Cambridge, UK: UIT. Retrieved from www. withouthotair.com.

4. Kleemann, M. (1991). Aktuelle wirtschaftliche und ökologische Probleme bei der Nutzung regenerativer Energiequellen. Elektrowärme Int., 49(A2), A62-A70.

5. UK Parliamentary Office of Science and Technology. (October 1, 2006). Carbon footprint of electricity generation. (POSTnote 06/268). Retrieved from http:// researchbriefings.parliament.uk/ResearchBriefing/ Summary/POST-PN-268.

6. China: Villagers protest at Zhejiang solar panel plant. (September 16, 2011). BBC News. Retrieved from http://www.bbc.co.uk/news/world-asia-pacific-14963354.

7. Miller, L. M., Gans, F., \& Kleidon, A. (2011). Estimating maximum global land surface wind power extractability and associated climatic consequences. Earth Syst. Dynam., 2, 1-12.

8. Jefferson, M. (2011). Energy efficiency and sustainability. In Proceedings of the 44th Session of the International Seminar on Nuclear War and Planetary Emergencies, Erice (Italy), August 19-24, 2011. 
9. Frondel, M., Ritter, N., Schmidt, C. M., \& Vance, C. (2010). Economic impacts from the promotion of renewable energies: The German experience. Energy Policy, 38, 4048-4056.

10. Poser, H., Altman, J., ab Egg, F., Granata, A., \& Board, R. (July 2014). Development and integration of renewable energy: lessons learned from Germany. Aldiswil, Switerland: Finadvice. Retrieved from http:// www.finadvice.ch/files/germany_lessonslearned_final_071014.pdf.

11. Atzeni, S., \& Meyer-ter-Vehn, J. (2004). The physics of inertial fusion: Beam plasma interaction, hydrodynamics, hot dense matter (Chapter 1). Oxford: Clarendon Press. Retrieved from http://fdslive.oup.com/ www.oup.com/academic/pdf/13/9780198562641.pdf.

12. Angulo, C., Arnould, M., Rayet, M., Descouvemont, P., Baye, D., Leclercq-Willain, C., Coc, A., Barhoumi, S., Aguer, P., Rolfs, C., Kunz, R., Hammer, J. W., Mayer, A., Paradellis, T., Kossionides, S., Chronidou, C., Spyrou, K., Degl'Innocenti, S., Fiorentini, G., Ricci, B., Zavatarelli, S., Providencia, C., Wolters, H., Soares, J., Grama, C., Rahighi, J., Shotter, A., \& Lamehi Rachti, M. (1999). A compilation of chargedparticle induced thermonuclear reaction rates. $\mathrm{Nucl}$. Phys. A, 656(1), 3-183.

13. Knaster, J., Arbeiter, F., Cara, P., Favuzza, P., Furukawa, T., Groeschel, F., Heidinger, R., Ibarra, A., Matsumoto, H., Mosnier, A., Serizawa, H., Sugimoto, M., Suzuki, H., \& Wakai, E. (2013). IFMIF: overview of the validation activities. Nucl. Fusion, 53(11), 116001.

14. Knaster, J., Ibarra, A., Abal, J., Abou-Sena, A., Arbeiter, F., Arranz, F., Arroyo, J. M., Bargallo, E., Beauvais, P. -Y., Bernardi, D., Casal, N., Carmona, J. M., Chauvin, N., Comunian, M., Delferriere, O., Delgado, A., Diaz-Arocas, P., Fischer, U., Frisoni, M., Garcia, A., Garin, P., Gobin, R., Gouat, P., Groe- schel, F., Heidinger, R., Ida, M., Kondo, K., Kikuchi, T., Kubo, T., Le Tonqueze, Y., Leysen, W., Mas, A., Massaut, V., Matsumoto, H., Micciche, G., Mittwollen, M., Mora, J. C., Mota, F., Nghiem, P. A. P., Nitti, F., Nishiyama, K., Ogando, F., O'hira, S., Oliver, C. Orsini, F., Perez, D., Perez, M., Pinna, T., Pisent, A., Podadera, I., Porfiri, M., Pruneri, G., Queral, V., Rapisarda, D., Roman, R., Shingalam, M., Soldaini, M., Sugimoto, M., Theile, J., Tian, K., Umeno, H., Uriot, D., Wakai, E., Watanabe, K., Weber, M., Yamamoto, M., \& Yokomine, T. (2015). The accomplishment of the engineering design activities of IFMIF/EVEDA: The European-Japanese project towards a $\mathrm{Li}(\mathrm{d}, \mathrm{xn})$ fusion relevant neutron source. Nucl. Fusion, 55(8), 086003.

15. Maisonnier, D., Cook, I., Sardain, P., Andreani, R., Di Pace, L., Forrest, R., Giancarli, L., Hermsmeyer, S., Norajitra, P., Taylor, N., \& Ward, D. (2005, April 13). A conceptual study of commercial fusion power plants. Final report of the European Fusion Power Plant conceptual study (PPCS). (EFDA-RP-RE-5.0).

16. Keilhacker, M., Gibson, P., Gormezano, C., Lomas, P. J., Thomas, P. R., Watkins, M. L., Andrew, P., Balet, B., Borba, D., Challis, C. D., Coffey, I., Cottrell, G. A., De Esch, H. P. L., Deliyanakis, N., Fasoli, A., Gowers, C. W., Guo, H. Y., Huysmans, G. T. A., Jones, T. T. C., Kerner, W., König, R. W. T., Loughlin, M. J., Maas, A., Marcus, F. B., Nave, M. F. F., Rimini, F. G., Sadler, G. J., Sharapov, S. E., Sips, G., Smeulders, P., Söldner, F. X., Taroni, A., Tubbing, B. J. D., von Hellermann, M. G., Ward, D. J., \& JET Team. (1999). High fusion performance from deuterium-tritium plasmas in JET. Nucl. Fusion, 39(2), 209-234.

17. Jacquinot, J., \& JET Team. (1999). Deuterium-tritium operation in magnetic confinement experiments: results and underlying physics. Plasma Phys. Control. Fusion, 41(3A), A13. 